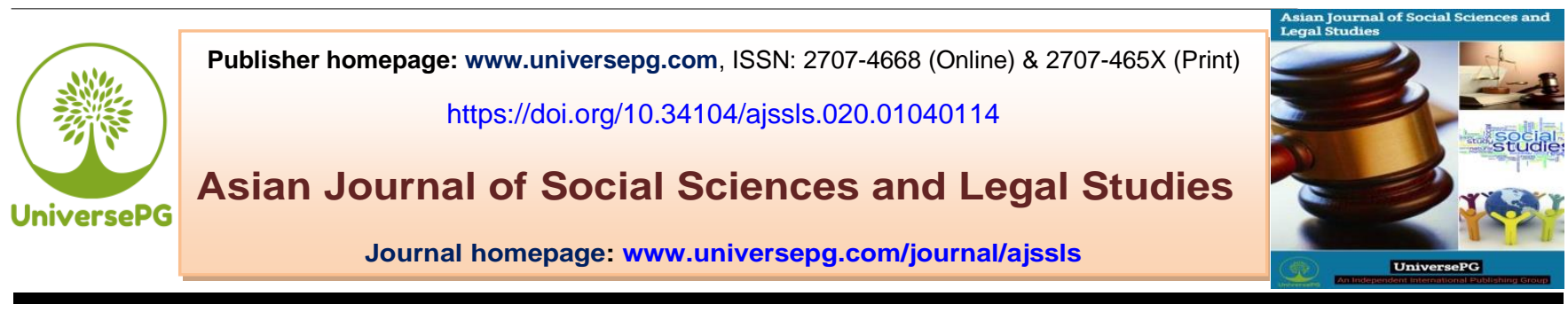

\title{
Fourth Industrial Revolution in Bangladesh: Prospects and Challenges
}

\author{
Maruf Hasan Rumi ${ }^{1}$, Md. Harunur Rashid ${ }^{2 *}$, Niaz Makhdum $^{1}$, and Nesur Uddin Nahid ${ }^{1}$ \\ ${ }^{1}$ Department of Public Administration, University of Dhaka, Dhaka, Bangladesh; and ${ }^{2}$ Department of Public Administration \\ and Governance Studies, Jatiya Kabi Kazi Nazrul Islam University, Trishal, Mymensingh, Bangladesh. \\ *Correspondence: harun_du.rashid92@yahoo.com (Md. Harunur Rashid, Lecturer, Department of Public Administration and \\ Governance Studies, Jatiya Kabi Kazi Nazrul Islam University, Trishal, Mymensingh, Bangladesh).
}

\begin{abstract}
The stream of globalization is impelling Bangladesh to adopt the technologies of the Fourth Industrial Revolution (FIR). This study examined the opportunities and problems created by the adoption of FIR in Bangladesh. Findings show that the adaptation of FIR can create enormous difficulties for the country with some new opportunities. Sustainable ICT development, increase in productivity, women, and citizen empowerment will bring positive effects. However, social inequality, colossal unemployment, a threat to social security, the domination of MNCs will increase that can harm the economy badly. FIR will also influence the political system. Hence, a comprehensive plan and sound policymaking can help to exploit the opportunity of FIR. Professional development training for human resources, job-based educational system, sensitive labor policies, alternative employment sector with updated technologies, investment in SMEs is expected to tackle the challenges of FIR in Bangladesh. Furthermore, the findings may be used to take the anticipatory role in the future for becoming a beneficiary of the FIR.
\end{abstract}

Keywords: Industrial revolution, Automation, ICT, Technology, LDC, Challenge, and Policy challenge.

\section{INTRODUCTION:}

The Fourth Industrial Revolution (FIR) has now become a buzzword, but still, most of the people are not much aware of how this new digital landscape will have a significant impact on their daily life. Technologies like Artificial Intelligence, Robotics, Virtual Reality, Biotechnology, Blockchain, 3D printing, and the Internet of things are taking the place of humans in different sectors (Park, 2018). However, the successful implementation of these modern technologies in a particular country depends on the cultures, norms, value systems, political and economic capacity of the country. Many scholars have predicted that the quality and productivity of industry products are enhanced by the successful transformation of the automation under the FIR (Ghobakhloo \& Fathi, 2019; Zhong et al., 2017). The volumes of works and jobs will have been expanded with the invention and development of various new technologies such as robotics, nanotechnology, and the automation process. However, there are also some risks to automation.

A recent study found that automation will substitute 800 million unskilled workers worldwide by 2030 (World Economic Forum, 2020). To cope with the technologies of the FIR, both developed and developing countries will face serious challenges. The developed nations perhaps face less risk than developing nations because of their advanced technologies and skilled human resources. 
But due to lack of skilled human resources, large scale investment, modern infrastructure, unstable political culture, and ineffective public policy, developing countries are lagging in the global market. South Asian developing countries such as India, Pakistan, Nepal, and Sri Lanka are also moving towards FIR. They are trying to adopt innovations of the FIR to upgrade their local industries (Adhikari, 2020; Rashid, 2020). Gradually Bangladesh is emerging as one of the fastest-growing economic power in South Asia with notable progress in many fields.

If Bangladesh can sustain this development rate, it is expected that Bangladesh will leave the Least Developed Country (LDC) category by 2024 (Kim, 2018). Innovations of FIR can be a vital force that can help Bangladesh to achieve its goal. But the journey towards institutionalisation of FIR is a humongous task for the government. The government needs to take appropriate policies to cope with the technological advancement of the FIR. Otherwise, the FIR will be a curse instead of a blessing for us. This study will forecast the political-economic condition under the FIR and will identify the opportunities and problems created by the adoption of FIR in Bangladesh.

\section{Study Objective:}

The main focus of the paper was -

○ To forecast the prospects and challenges created by the adoption of FIR in Bangladesh.

\section{Literature Review}

Industrial revolutions lead to economic, political, and societal changes over a few centuries by developing and introducing new technologies. These technological changes also represent the three major phases of revolutions. The first industrial revolution refers to mechanical production, which emerged in the United Kingdom in the late 18th century (Frey \& Osborne, 2017). At that time, the workplace culture was dominated by men, and women were forced out of production positions (Philbeck\& Davis, 2018). Macpherson (1962) stated that this revolution has rapidly increased capacity in production, which leads to urbanisation, the development of local and global market economies, the importance of democratic governments, and an increasing middle income in the western hemisphere. The second industrial revolution was known as a technological revolution that emerged from the late $19^{\text {th }}$ century to the early $20^{\text {th }}$ century due to natural resources, firm government policy, and abundant labor supply (Frey \& Osborne, 2017; Smil, 2005).

Entrepreneurs and businessmen applied technology to manufacturing ends, and the period saw a boom with products that were the direct results with science and engineering themselves (Hughes, 2004). At that time, new technologies were introduced and developed (steamship, telephone, gas turbine, artificial fertiliser, railroads, electric light, and typewriter, etc.) led to mass industrial production, maintaining standardization of products, development of large-scale technological infrastructure, accuracy manufacturing and the emergence of public transportation based on combustion engine (Philbeck \& Davis, 2018). Although the Third Industrial Revolution emerged in 1960, it had started in earnest after the Second World War (Frey \& Osborne, 2017). This revolution had introduced and developed the personal computer, and the internet led to the democratisation of information, price reduction, and rapid quality improvement, presented as a new era of capitalism; reform the economic structure for a war-torn world, making calculation easier for business and governments (Philbeck \& Davis, 2018). Moving on in the work environment of the world is often portrayed as the FIR or 4.0, which is defined by introducing new technologies like genetics, artificial intelligence, wireless technologies advancement, cyber-physical system, cloud computing, internet of thing, nanotechnology, biotechnology, and 3-D printing (Schwab, 2017).

Brynjolfsson and McAfee (2014) mentioned this revolution as the second machine age through their widely famous book and argued that the main distinct from previous industrial revolutions is the current technologies at replacing cognitive labor and human employees altogether. Besides, the FIR refers to the digitisation and automation of work, which will dramatically change working nature, business styles, and cultural phenomenon in the upcoming decades (Arntz, Gregory, \& Zierahn, 2016; Brynjolfsson \& McAfee, 2014; Ford,2015; Frey \& Osborne, 2017). 
This literature also will cover different perspectives like politics, economics, and business, etc. From economics \& business perspective, the FIR will bring a radical improvement in the economy and business. However, 800 million unskilled workers over the world will lose their job by 2030 (World Economic Forum, 2020). On the contrary, FIR transforms the existing production system into a better manufacturing process that will add a new dimension to the future industry by developing cyber-physical systems and incorporating advanced technology (Schwab 2017 \& Zhou et al., 2016).

Mokyr et al. (2015) also have explained that industrial automation can increase efficiency and productivity, which helps to decrease the prices of the goods, and can increase the demand for that commodity, resulting in new labor demand for jobs in those industries. On the other hand, mass unemployment over the next few decades is unlikely to pose a big problem due to the widespread practice of automation processes in industries (Arntz et al., 2016; Autor, 2015; Furman, 2016). The World Bank estimated in 2019 that approximately 57 percent of jobs in OECD countries, 77 percent jobs in China, and 47 percent of jobs in the USA would be at risk due to the increase of automation. The government has to need reforming the existing policies and plans to cope with the technologies of FIR. Zervoudihas conducted a study about FIR in 2019. He argued that as FIR is wholly related to socioeconomic growth, the government will act to minimise the risk of workers being subjected to automation by investing in learning and skills for unskilled labors so that they can respond better to emerging technology and digitisation.

He also further added that governments should support the practical education and training in new technologies, build a strong link between education and the labor market, emphasise STEM (Science, Technology, Engineering, and Mathematics) training of young people to adapt 4.0. Besides, FIR led to a wide gap of income inequality where only 8 percent of the total population of the world earns half of the entire world's income, and the remaining other half income is earned by 92 percent of the world's population (Arntz et al., 2016). Some analysts have said that people from developing countries would feel confused UniversePG I www.universepg.com and challenged structurally over the FIR concept. It has therefore taken time to apply and incorporate the essential elements of FIR and to gain advantage from it (Drath \& Horch, 2014; Schläpfer et al., 2015; Gilchrist, 2016; Ludwig et al., 2018; Lasi et al., 2014).

Emerging and developing countries, such as India, Pakistan, Indonesia, Brazil, Malaysia, Nigeria, and Thailand, have tried to adapt the FIR (Bahrin et al., 2016; Iyer, 2018; Ezenwa et al., 2018; Berawi, 2018). Bangladesh is a little far away from the facilities of FIR. Still, it is not hard for the country if it concentrates on infrastructure development and technology integration because of the availability of technological imports and new settings (Gilchrist, 2016; Walcott, 2017). Experts predicted that if the government can increase the support for the integration of FIR, the economic progress of the country will contribute to a more robust economy in South Asia. Islam et al. (2018) identified poor infrastructure, availability of cheaper and unskilled labor, expensive installation of new technologies, lack of government support \& knowledge as the critical challenges for Bangladesh in this regard. From the above literature, it can be summarised that most of the studies related to the overall impact of FIR in the world, and very few have been discussed on FIR in Bangladesh. Even so, these few studies predict the possible outcome of the FIR on particular sectors, but no comprehensive study was found on this topic.

\section{METHODOLOGY:}

This study reported findings through a qualitative investigation. Qualitative data was collected to explain complex phenomena on the economic and political impact of FIR in the Bangladesh context. This study employs an explorative case study and a traditional qualitative approach that focuses on FIR. These data collection methods were essential to visualise the myriad information about the impacts of FIR on the political sector to adopt the new economic system of upcoming years. To conduct this paper, primary and secondary data were used. Secondary data was gathered from different journals, books, and international as well as government reports on this particular issue through inductive content analysis. Content analysis is the methodical explanation of the 
context by presenting the answer of 'who', 'what', 'where', and 'how 'questions following the defined rules to avoid any biases (Fraenkel and Wallen, 2008; Islam, 2013).

A multi-dimensional data collection method was used for this study. Here semi-structured interviews and documentation surveys were conducted for collecting data from respondents. The multi-method research protocol is especially useful when approaching topics in which intercultural interaction is obscured by phenomena grounded for a deep understanding of the political-economic impact of FIR.

We had selected three categories of participant's academicians, experts, and businessmen. These persons have more accurate knowledge to predict the future condition of FIR in Bangladesh. So, we choose purposively 30 participants to get more meaningful information in a limited time. As similar information was coming from the interviews, therefore we stopped taking further interviews after taking 15 interviews. The main themes of the report were identified based on the transcription of all the interviews. A triangulation approach was used for data procedure. The researcher (s) use a triangulation approach to avoid the limitations of a single method, which helps to increase the reliability and validity of data. For analysing data, a thematic approach was employed, which helps to expand the already established horizons of knowledge. For preparing this paper, all sorts of data were managed carefully; ethical issues were considered strictly and followed the ethical guidelines of Miles and Humberman (1995).

\section{RESULTS AND DISCUSSION:}

Bangladesh is trying to raise awareness among the stakeholders about the FIR concept and encourage entrepreneurs to incorporate new technologies to get benefits from it. However, this transformation process towards FIR will create both positive and negative impacts in different sectors. Experts predicted five crucial sectors that needed to be focused by the government to take adaptation policies while going through this transformation. These sectors are briefly discussed below-

UniversePG I www.universepg.com

\subsection{Governance system in the upcoming decade -} FIR will create an opportunity to adopt innovations in political systems. The pattern of vote casting, election time violence, as well as the political manifesto of the political parties, will be changed. Digital platforms will be used for election campaigning, and intelligent voting systems will be introduced. The country will move into a new administrative paradigm called the future digital e-governance system. According to Md. Atique Rahman, Department of International Relations, University of Dhaka (personal communication, January 20, 2020), "The manifesto of the government will be centralised to digital development, and there will be a paradigm shift of the administrative system from New Public Service to the future e-governance."

Democracy will face a lot of challenges in the upcoming decade. The demand of the people will be changed, and political leaders will need new ideologies to tackle the modern social complexities under the FIR. Political polarisation will be so evident in national politics, which will create an extreme environment in the political arena. Due to the domination of capitalists in the political system, antigovernment populism will rise, and that will drive the mass population towards movement against capitalist systems. As per an interview with a senior professor of Dhaka University, "Acute social and economic inequality will force people to raise their voice to fulfill their demand, leading to resurrect socialism in Bangladesh" (M. Nuruzzaman, personal communication, January 22, 2020).

Automation in the service delivery system will make the public service more available for the citizens and ensure transparency in the working procedure of the government. Massive public sector reform will take place, and maintaining this transformation will be a tremendous challenge for the political leaders. Hence some radical change is brought under the government's flagship A2I program to make the government sector versatile, efficient, and competitive. For example, 4,554 Union Digital Centers, more than 100 streamlined public services, e-procurement, and smart health cards are moving Bangladesh along the FIR track (World Economic Forum, 2018, Rashid, 2020). According to the prediction of a Professor of political science, FIR will help citizens to participate in 
governments' policymaking and reduce the communication gap between the government and citizens (N. Parvin, personal communication, January 20, 2020).

\subsection{Inequality forced by this new production system}

- Under the new production system, through automation and artificial intelligence, the time and cost of production will reduce, and the benefits of industrialists will increase. However, the labor-based production system will alter with capital-based techniques, causing dehumanisation in the production line (Sun, 2018). In this matter, the president of the Metropolitan Chamber of Commerce and Industry said (Kabir, 2019), "Due to automation, labor market trends will show a gradual shift to jobs that require higher skill levels. New technology does not simply make people redundant; instead, it reduces the labor required for a given level of production." A lot of people will be jobless. Concurrently, income inequality will rise drastically.

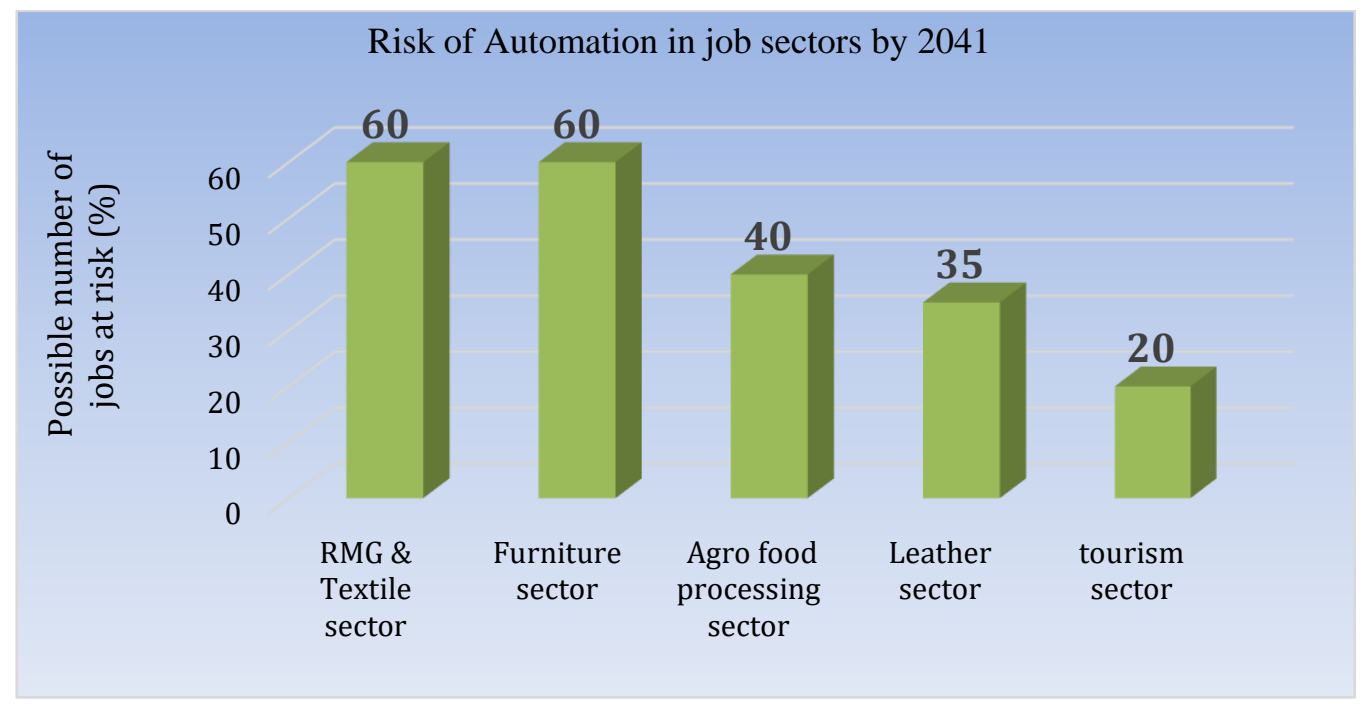

Fig 1: Risk of Automation in job sectors by 2041. Adapted from Finding Emerging Occupations to Tackle the Challenges of Automation in Bangladesh, by a2i, august 2019.

According to the Executive Director of RK group of industries (AJ Chowdhury, personal communication, January 20, 2020), "We witnessed a "Digital Divide" during the Third Industrial Revolution, which is about the epoch of ICT. The privileged people who have sagacity in the digital landscape could take on the new jobs. So if the technology is in the hands of a few wealthy people, then the state of injustice worsens." Most of the respondents reflected the same and supported that statement in their discussion.

As women possess poor knowledge on the technical side, they will face difficulties in the era of FIR (Moktadir, 2018). So, it can be predicted that this revolution will also increase gender discrimination in our country. According to S. Noman (personal communication, January 23, 2020), "Automation will increase gender discrimination, but there is no effective gender-sensitive policy in our country to upskill the women workforce."

As the FIR created social inequality, the general people possess a negative impression about this, where the industrialists are positive because they are the beneficiaries of the FIR. The government is in a policy dilemma as industrialists are the source of finance, and the mass people are considered as vote banks (Gordon, 1981).

\subsection{Security concerns under the Fourth Industrial} revolution- FIR will have a crucial impact on state and private security. The security system of the country will be updated with the introduction of robotics in the security forces. The military force will be equipped with AI soldiers. The efficacy of risky operations will be increased by employing bomb disposing of robots, surveillance, and attack drones. According to an 
associate professor of Jagannath University, "Because of reserving citizens' information on the public server, the crime rate will be reduced by using digital fabrication that helps the government to identify any criminals easily" (N. Mahfuz, personal communication, January 25, 2020).

On the contrary, information is said to be the most powerful weapon if they are in the hand of evil people. Misuse of technological Knowledge will create risk for national security. Moreover, we lack technical experts that force us to hire external experts from abroad, which will decrease the control of the state authority over some sectors. In this issue, an AD of NILG (National Institute of Local Government) opined, "The confidentiality of state policy will be confronted, and the government will lose control in the market because of cryptocurrencies" (M. Imran, personal communication, January 28, 2020).

Domination of Multinational Companies (MNCs) will also be a key concern for the government. MNCs collect the personal information of the employees \& clients by introducing a biometric registration system and NID card information. In this issue, a Professor of Dhaka University opined, "Technologically developed countries are trying to dominate our economy through MNCs by using our low-cost labor and information" (S. Ahmed, personal communication, January 22, 2020).

\subsection{Education and ICT sector change in future -}

The FIR will bring a major challenge for the education sector as Bangladesh promotes education to its students through didactic pedagogy. A Large scale vocational and practical training program is needed to be integrated with the existing education system. A recent study report shows that $60 \%$ in low education, $48 \%$ in medium, and $19 \%$ in higher education jobs will be displaced by automation (Price water house Coopers, 2018). A lecturer of Jagannath University said, "The education system in Bangladesh is quantitative rather than qualitative. More focus should be given on STEM to conduct MOOC, Life-long Learning, and Blended instruction, optimisation of flipped and online courses, as well as to confer degrees through online. Concurrently, teachers have to focus on flip learning where they teach their students following a UniversePG I www.universepg.com different method to prepare the future generation ready for combating the challenge of the $4^{\text {th }}$ industrial revolution." (A. Ehsan, personal commu-nication, January 18, 2020).

To cope with this situation, about 43000 people are given training under the Access to Information (A2I) project (A2I, 2020), and almost four lakhs people get training under the Skills For Employment Investment Program (SEIP) program (Skills for Employment Investment Program, 2020). Moreover, the government has to focus on different issues to lead the FIR, such as personalisation of education (designing for an individual's changing needs, unique talents, and interests, an engine for rapid growth, lower costs, and greater profits), specialisation of education (advance technological knowledge). About this issue, a lecturer of Independent University, Bangladesh, said, "To facilitate the FIR, skilled workforce and developed infrastructure are needed which can be ensured by proper educational systems. But our country's educational system is quite inverse to the job sectors" (A.Hossain, personal communication, January 18, 2020).

\subsection{Global trade structure and future of business in}

Bangladesh - The international community acknowledges the FIR positively, and they agree that numerous tech companies will dominate the global market in the upcoming period for their intellectual advancement in the field of international trade. At that time, the demand for software will rise. Former VC of Shahjalal University of Science and Technology opined, "The FIR will create new business opportunities like a software business. Bangladesh ranked 2nd in exporting software and expected to expand this business." (M.U.Ahmed, personal communication, January 15, 2020).

Besides this, our indigenous company will have an opportunity to compete with the MNC. Technical capacity and innovation will help them to establish a strong position in their market (Abdin, 2019). As per a senior professor of philosophy, University of Dhaka, "FIR will facilitate the SMEs in online business using new digital landscape, and also they will have to face the domination of MNC as they have more capital." (F. Uddin, personal communication, January 26, 2020). 
However, many countries are using technological assistance instead of unskilled labor in their industries. The demand for labor will decrease, and the capitaloriented countries will adopt a protectionist policy in importing labor. Moreover, it will create an adverse impact in a country like Bangladesh, where foreign currencies by technologically unskilled labor contribute $35 \%$ of export earnings (Hasan et al., 2018).

\section{CONCLUSION \& POLICY IMPLICATION:}

The FIR is adding significant dimensions in all spheres of the world. It is expected that the stream of the FIR is going to take the top place in Bangladesh in the upcoming decade. This flow will drop a significant impact on national politics and economics. This study has presented that Bangladesh is a little bit prepared to face the changes and challenges of the revolution. The challenges of FIR for a Graduating LDC like us are lack of talented resources, expertise, and better cloud networking, poor infrastructure, huge unskilled population, lack of legal and proper policy support, etc. Alternatively, FIR will bring some positive implications also, with the increase in productivity, sustainable ICT development, women empowerment, citizen empowerment, etc. The adoption of FIR will create significant complexities in our country. This study has revealed that inequality, gender discrimination, unemployment, cyber-crime, the dominance of MNC over SMEs will increase. The most important thing is that the Political system of our country will be influenced in the next decade by the stream of FIR. To minimise the problems and to get benefits from FIR, the government should take effective policies with defined plans at the current period. Despite revealing these results, this study has some limitations like every other research that created a barrier from getting a neutral, practical, and qualitative outcome. The main drawback of this research is that it was time-consuming, and the verification of the result was difficult. It was a labor-intensive study, and the analysis was complex. On the contrary, the findings of this study couldn't be extended to a broader population with the same degree of certainty. Despite these limitations, this study brought a more-clear picture about the impact of the FIR in Bangladesh.

UniversePG I www.universepg.com
The policies for accepting FIR in our country require it to be based on proper research, and for this purpose, integration of universities in research activities is emergent. This will help to take the appropriate policy and plan for any dramatic situation. In our country, the government takes jumping systems without any research to serve the interest of their political allies, and as a result, this creates difficulties for us. The government should make policies to transfer knowledge and information to the local industries and to collaborate with educational institutions. To achieve this goal, the private sector should also work along with the government. The private sector should take initiatives to develop and mobilise the skills of human resources according to the demand of the job market of both Bangladesh and other countries. They should also invest in infrastructural development and make a proper strike balance. Finally, it can be concluded that planning should be made in the adjustment or talking period, and the government needs to be anticipatory about the future of the country for becoming a beneficiary of the FIR.

\section{ACKNOWLEDGEMENT:}

Authors would like to thank Department of Public Administration for providing continuous support and also grateful to $\mathrm{Md}$ Minhajul Abedin, A.M.M Mubassher Shah, Shukti Bala, and Md Shakil Hossain who contributed in data collection and processing them.

\section{CONFLICTS OF INTEREST:}

There is no conflict of interest from the authors' end.

\section{REFERENCES:}

1) A2I, (2020). Skills for Decent Employment. https://a2i.gov.bd/skills/

2) Abdin, M. (2019). $4^{\text {th }}$ Industrial Revolution and Reality of Industrialisation in Bangladesh. Available at SSRN 3319582. Retrieved from https://papers.ssrn.com/sol3/papers.cfm?abstract _id $=3319582$

3) Adhikari, R. (2020). Harnessing the Potential of the Fourth Industrial Revolution in South Asia. In Trade and Regional Integration in South Asia. Springer, Singapore, p. 295-319. https://link.springer.com/chapter/10.1007/978981-15-3932-9_16 
4) Arntz, M., Gregory, T., \& Zierahn, U. (2016). The risk of automation for jobs in OECD countries.Retrieved from - https://www.oecdilibrary.org/social-issues-migration-health/therisk-of-automation-for-jobs-in-oecdcountries 5jlz9h56dvq7-en

5) Autor, D. H. (2015). The paradox of abundance: Automation anxiety returns. Performance and progress: Essays on capitalism, business, and society, 237-260.

6) Aziz, A. (2018). ICT Policy Challenges for Digital Inclusion in Bangladesh (Doctoral dissertation, Vrije Universiteit Brussel). https://www.researchgate.net/publication/332171 057_ICT Policy_Challenges for_Digital_Inclusi on_in_Bangladesh_Evaluating_Policy_and_Prac tice

7) Bahrin, M.A.K., Othman, M.F., Azli, N.N., \& Talib, M.F. (2016). Industry 4.0: A review on industrial automation and robotics. Jurnal Teknologi, 78(6-13), 137-143.

https://www.researchgate.net/publication/304614

356 Industry 40 A review on industrial auto mation and robotic

8) Bangladesh. Ministry of Education. (2011). National skills development policy: 2011.

9) BDI. (2016). What is industry 4.0. https://english.bdi.eu/article/news/what-isindustry-40/.

10) Berawi, M.A. (2018). Utilising big data in industry 4.0: Managing competitive advantages and business ethics. International Journal of Technology, 3(1), 430-433.

https://www.researchgate.net/publication/324831 345_Utilizing_Big_Data_in_Industry_40_Manag ing Competitive Advantages and Business Et hics

11) Brynjolfsson, E., \& McAfee, A. (2014). The second machine age: Work, progress, and prosperity in a time of brilliant technologies. WW Norton \& Company.

https://www.amazon.com/Second-Machine-AgeProsperity-Technologies-ebook/dp/B00D97H PQI

12) Drath, R., \&Horch, A. (2014). Industrie 4.0: Hit or hype? IEEE Industrial Electronics Magazine, 8(2), 56-58.
13) Easton, D. (1965). A framework for political analysis. Englewood Cliffs, NJ: Prentice-Hall. https://www.amazon.com/Framework-Polit ical-Analysis-Prentice-Hall-Contemporary/ $\mathrm{dp} / 0133301834$

14) ECONOMY, I. F. T. B. A. (2017). SKILLS 2030.

15) Ezenwa, O., Stella, A., \&Agu, A.O. (2018). Effect of competitive intelligence on competitive advantage in innoson technical and industry limited, Enugu State, Nigeria. International Journal of Business, Economics \& Management, 1(1), 28-39. https://doi.org/10.31295/ijbem.v1n1.25

16) Ford, M. (2015). Rise of the Robots: Technology and the Threat of a Jobless Future. Basic Books. Retrieved from https://www.amazon.com/Rise-Robots-Tech nology-Threat-Jobless-ebook/dp/B00PWX7 $\underline{\mathrm{RPG}}$

17) Frey, C. B., \& Osborne, M. A. (2017). The future of employment: How susceptible are jobs to computerisation? Technological forecasting and social change, 114, 254-280.

https://www.sciencedirect.com/science/article/ abs/pii/S0040162516302244

18) Furman, J. (2016). Is this time different? The opportunities and challenges of artificial intelligence. presentation, AI Now: The Social and Economic Implications of Artificial Intelligence Technologies in the Near Term, New York, NY. Retrieved from -

https://obamawhitehouse.archives.gov/sites/de fault/files/page/files/20160707_cea_ai_furman .pdf

19) Ghobakhloo, M., \& Fathi, M. (2019). Corporate survival in Industry 4.0 era: the enabling role of lean-digitised manufacturing. J.of Manufacturing Technology Mana-gement. https://www.researchgate.net/publication/338204 494_Industry_40_Digitization_and_Opportunitie s_for_Sustainability

20) Gilboy, G.J. (2016). The Myth behind China's miracle. In seeking changes: The Economic development in contemporary China, pp. 1-16. https://www.foreignaffairs.com/articles/asia/200 4-07-01/myth-behind-chinas-miracle 
21) Gilchrist, A. (2016). Introducing Industry 4.0. Apress, Berkeley, CA. Retrieved from https://link.springer.com/chapter/10.1007/978-14842-2047-4_13

22) Gilchrist, A. (2016). Industry 4.0: The industrial internet of things. Retrieved from https://www.amazon.com/Industry-4-0-Industrial-Internet-Things/dp/1484220463

23) Gordon, A. (1981). The Iron Triangle: The Politics of Defense Contracting. New York. Retrieved from https://www.foreignaffairs.com/reviews/capsulereview/1982-03-01/iron-triangle-politics-defense-contracting

24) Haller, S., Karnouskos, S., \& Schroth, C. (2008). The internet of things in an enterprise context. In Future Internet Symposium (pp. 14-28). Springer, Berlin, Heidelberg. https://doi.org/10.1007/978-3-642-00985-3 2

25) Hasan, S. B., Akhter, R., \&Saha, S. (2019). Impact of Remittance on Economic Growth in Bangladesh. American Journal of Trade and Policy, 6(1), 41-48.

26) Hofmann, E., \&Rüsch, M. (2017). Industry 4.0 and the current status as well as future prospects on logistics. Computers in Industry, 89(1), 23-34.

https://doi.org/10.1016/j.compind.2017.04.002

27) Hughes, T. P. (2004). A Century of Invention and Technological Enthusiasm. Retrieved from - https://www.amazon.com/Thomas-Hug hes-Invention-Technological-Enthusiasm/dp/ B008VQVM66

28) Islam, M. A., Jantan, A. H., Hashim, H., Chong, C. W., \& Abdullah, M. M. (2018). Fourth Industrial Revolution in Developing Countries: A Case on Bangladesh. Journal of Management Information and Decision Sciences (JMIDS), 21(1). https://doi.org/1532-5806-2

29) Iyer, V. G. (2018). Strategic Environmental Assessment (SEA) Process for Sustainable Industrial Automation, Electrical, Mechanical and Robotics Systems Sustainabilty Excellence Achievements. DEStech Transactions on Engineering and Technology Research, (ecae).
30) Joveda, N., Khan, M. T., Pathak, A., \&Chattogram, B. (2019). Cyber Laundering: A Threat to Banking Industries in Bangladesh: In Quest of Effective Legal Framework and Cyber Security of Financial Information. International Journal of Economics and Finance, 11(10), 54-65. https://doi.org/10.5539/ijef.v11n10p54

31) Kabir, N. (2019, August). Future Skills: Finding Emerging Occupationsto Tackle the Challenges of Automation In Bangladesh. In N.M. Alam, National Consultation on i4.0 and Future of Work. Organised by UNIDO and a2i, Dhaka. Retrieved from -

https://a2i.gov.bd/publication/automation-inbangladesh

32) Kim, N. (2018). Prospects of Least Developed Countries meeting the graduation criteria by 2030. UN CDP Policy Review, (8). https://papers.ssrn.com/sol3/papers.cfm?abstract id=3299977

33) Lasi, H., Fettke, P., Kemper, H., Feld, T., \& Hoffmann, M. (2014). Industry 4.0. Business \& Information Systems Engineering, 6(1), 239-242. https://doi.org/10.1007/s12599-0140334-4

34) Lee, J., Kao, H.A., \& Yang, S. (2014). Service innovation and smart analytics for industry 4.0 and big data environment. Procedia Cirp, 16(1), 3-8.

https://papers.ssrn.com/sol3/papers.cfm?abstract id $=3417813$

35) Lotti, G., Villani, V., Battilani, N., \& Fantuzzi, C. (2018). Towards an integrated approach for supporting the workers in Industry 4.0. In IEEE Industrial Cyber-Physical Systems (ICPS), pp. 609-614. https://doi.org/10.1109/ICPHYS.2018.8390775

36) Ludwig, T., Kotthaus, C., Stein, M., Pipek, V., \&Wulf, V. (2018). Revive old discussions! Socio-technical challenges for small and medium enterprises within industry 4.0. In Proceedings of $16^{\text {th }}$ European Conference on Computer-Supported Cooperative WorkExploratory Papers. European Society for Socially Embedded Technologies (EUSSET). https://doi.org/10.18420/ecscw2018_15 
37) Macpherson, C. B. (1962). The Unfinished Revolution: An Essay on the Sources of Influence of Marxism and Communism. Retrieved from https://www.jstor.org/stable/2146334?seq=1\#met adata_info_tab_contents

38) Moktadir, M. A., Ali, S. M., Kusi-Sarpong, S., \& Shaikh, M. A. A. (2018). Assessing challenges for implementing Industry 4.0: Implications for process safety and environmental protection. Process Safety and Environmental Protection, 117, 730-741. https://doi.org/10.1016/j.psep.2018.04.020

39) Mokyr, J., Vickers, C., \& Ziebarth, N. L. (2015). The history of technological anxiety and the future of economic growth: Is this time different? Journal of economic perspectives, 29(3), 31-50.

https://www.aeaweb.org/articles?id=10.1257/jep. $\underline{29.3 .31}$

40) Moving from industry 2.0 to industry 4.0: A case study from India on leapfrogging in smart manufacturing. Procedia Manufacturing, 21(1), 663-670.

https://doi.org/10.1016/j.promfg.2018.02.169

41) Nazneen, S., Hossain, N., \& Sultan, M. (2011). National discourses on women's empowerment in Bangladesh: continuities and change. IDS Working Papers, 2011(368), 1-41. https://onlinelibrary.wiley.com/doi/abs/10.1111/j .2040-0209.2011.00368_2.x

42) Park, S. C. (2018). The Fourth Industrial Revolution and implications for innovative cluster policies. AI \& SOCIETY, 33(3), 433445.

https://link.springer.com/article/10.1007/s00146$\underline{017-0777-5}$

43) Philbeck, T., \& Davis, N. (2018). The Fourth Industrial Revolution. Journal of International Affairs, 72(1), 17-22. https://www.jstor.org/stable/26588335?seq=1\#m etadata_info_tab_contents

44) PricewaterhouseCoopers, (2018). Industry 4.0Opportunities and Challenges of the Industrial Internet. Retrieved from https://www.pwc.nl/en/assets/documents/pwcindustrie-4-0.pdf

UniversePG I www.universepg.com
45) Rashid MH. (2020). Prospects of digital financial services in Bangladesh in the context of fourth industrial revolution, Asian J. Soc. Sci. Leg. Stud., 2(5), 88-95. https://doi.org/10.34104/ajssls.020.088095

46) Rüßmann, M., Lorenz, M., Gerbert, P., Waldner, M., Justus, J., Engel, P., \& Harnisch, M. (2015). Industry 4.0: The future of productivity and growth in manufacturing industries. Boston Consulting Group, 9(1), 5489.

https://www.bcg.com/publications/2015/engineer ed_products_project_business_industry_4_future _productivity_growth_manufacturing_industries

47) Schläpfer, R.C., Koch, M., \& Merkhofer, P. (2015). Industry 4.0 challenges and solutions for the digital transformation and use of exponential technologies. Deloitte, Zurique. Retrieved from -

https://www2.deloitte.com/content/dam/Deloitte/ ch/Documents/manufacturing/ch-en-manufac turing-industry-4-0-24102014.pdf

48) Schwab, K. (2017). The fourth industrial revolution. Currency. Retrieved from https://www.penguinrandomhouse.com/books/55 1710/the-fourth-industrial-revolution-by-klausschwab/

49) SEIP (2020). Skills for Employment Investment Program. https://seip-fd.gov.bd/

50) Smil, V. (2005). Creating the twentieth century: Technical innovations of 1867-1914 and their lasting impact. Oxford University Press. Retrieved from https://www.jstor.org/stable/40061298?seq=1\#m etadata_info_tab_contents

51) Sun, M. (2018). The Impacts of the Fourth Industrial Revolution on Jobs and the Future of the Third Sector. Retrieved from https://www.nicva.org/sites/default/files/d7conte nt/attachments-articles/the_impact_of_the_4th_ industrial revolution on jobs and the sector.pdf

52) Trappey, A.J., Trappey, C.V., Govindarajan, U.H., Chuang, A.C., \& Sun, J.J. (2017). A review of essential standards and patent landscapes for the Internet of Things: A key enabler for industry 4.0. Advanced Engineering Informatics, 33(1), 208-229. https://doi.org/10.1016/j.aei.2016.11.007 
53) Walcott, S. M. (2017). Chinese Science and Technology Industrial Parks. Routledge. https://doi.org/10.4324/9781315198170

54) Witkowski, K. (2017). Internet of things, big data, industry 4.0-Innovative solutions in logistics and supply chains management. Procedia Engineering, 182(1), 763-769. https://doi.org/10.1016/j.proeng.2017.03.197

55) World Economic Forum, (2020). Bend, don't break: how to thrive in the Fourth Industrial Revolution. Retrieved from https://www.weforuhttps//www.weforum.org/ag enda/2020/01/the-fourth-industrial-revolution-ischanging
56) World Economic Forum. (2017). The global competitiveness report 2016-2017. https://www.weforum.org/reports/the-globalcompetitiveness-report-2016-2017-1

57) Zhong, R. Y., Xu, X., Klotz, E., \& Newman, S. T. (2017). Intelligent manufacturing in the context of industry 4.0: a review. Engineering, 3(5), 616-630.

https://www.sciencedirect.com/science/article/pii /S2095809917307130

58) Zhou, G. B., Wu, J., Zhang, C. L., \& Zhou, Z. H. (2016). Minimal gated unit for recurrent neural networks. International Journal of Automation and Computing, 13(3), 226-234. https://link.springer.com/article/10.1007/s11633016-1006-2

Citation: Rumi MH, Rashid MH, Makhdum N, and Nahid NU. (2020). Fourth industrial revolution in Bangladesh: prospects and challenges, Asian J. Soc. Sci. Leg. Stud., 2(5), 104-114. https://doi.org/10.34104/ajssls.020.01040114 क) के 